\title{
Antiphospholipid antibodies and COVID-19 thrombotic vasculopathy: one swallow does not make a summer
}

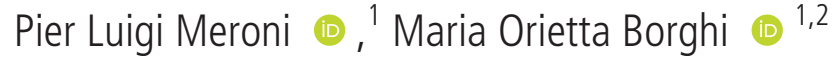

The high morbidity and mortality of COVID-19 have been associated with the thrombotic microangiopathy described in the patients in addition to the increased prevalence of thrombosis affecting medium/ large arterial and venous vessels. ${ }^{1}{ }^{2}$ Initial reports demonstrating prolonged activated partial thromboplastin times (aPTT) and positivity for antiphospholipid antibody (aPL) assays raised the issue of whether common pathogenic mechanisms were shared by the antiphospholipid antibody syndrome (APS) and COVID-19. ${ }^{3} 4$ In particular, the systemic thrombotic microangiopathy and the increased circulating levels of proinflammatory cytokines underlined the similarity between catastrophic APS (CAPS) and COVID-19. ${ }^{5}$

The similarities between APS/CAPS and COVID-19 are even more complex and intriguing as summarised in table 1. A proinflammatory environment that includes the activation of the complement system has been reported in all these conditions, although at different degrees. The involvement of several cell types playing a role in the coagulation cascade, such as platelets, monocytes and neutrophils, has been described which is closely associated with the proinflammatory and prothrombotic phenotypes. ${ }^{78}$ In particular, an endothelial perturbation is generally thought to be a common denominator in these diseases and several authors described it with the term 'endothelitis' in the COVID-19.9-11

Both proinflammatory cytokine (eg, interleukin-6) and complement activation products (ie, C5a and C5b9) were thought to play a role in mediating the endothelitis together with a direct effect of SARS-CoV-2 on the endothelium. ${ }^{10-12}$ However, the

${ }^{1}$ Experimental Laboratory of Immunological and Rheumatologic Researches, Istituto Auxologico Italiano-Istituto di Ricovero e Cura a Carattere Scientifico, Milano, Italy

${ }^{2}$ Department of Clinical Sciences and Community Health, Università degli Studi di Milano, Milano, Italy

Correspondence to Professor Pier Luigi Meroni, Experimental Laboratory of Immunological and Rheumatologic Researches, Istituto Auxologico Italiano-Istituto di Ricovero e Cura a Carattere Scientifico, 20145 Milano, Italy; pierluigi.meroni@unimi.it
SARS-CoV-2 endothelial tropism is still a matter of debate despite the presence of the entry molecule (ie, ACE2) on the endothelial surfaces. ${ }^{13}$ So, it is not surprising that additional potential mediators of endothelial perturbation have been suggested. In particular, aPL came into the limelight because of their well-known ability to bind and activate endothelium in the APS. ${ }^{14}$

aPL can be formally identified by functional PL-dependent coagulation assay (ie, the so-called lupus anticoagulant (LA) test) and by solid phase methods that detect antibodies against beta2 glycoprotein I ( $\beta 2 \mathrm{GPI})$ (ie, anticardiolipin and anti- $\beta 2$ GPI assays) or prothrombin complexed with phosphatidylserine (ie, aPS/PT). These two last families of autoantibodies are responsible for the large majority of the positive LA. ${ }^{14}$ The papers reporting positive aPL tests in patients with COVID-19 are quite heterogeneous regarding frequency and biochemical characteristics of these autoantibodies; in particular, their clinical impact on the disease did not emerge in a recent meta-analysis and systematic review. ${ }^{15}$

Some variables can affect the reproducibility of the functional LA assay, and specific caveats have been underlined by the international scientific societies to avoid misinterpretation. For example, concomitant anticoagulant therapy (eg, heparin) and systemic inflammation with high C-reactive protein plasma levels are well-known factors that can produce LA false-positive results. ${ }^{16} 17$ On the other hand, aPL solid phase tests are not affected by anticoagulant therapy or inflammation mediators.
The positivity for LA in the absence of anti- $\beta 2$ GPI and aPS/PT is usually considered of low diagnostic and prognostic value in the setting of APS and systemic autoimmune rheumatic diseases. ${ }^{18} 19$ Likewise, the high frequency of isolated positive LA (and prolonged aPTT) in most of the published COVID-19 papers casts doubts on the true presence of thrombophilic aPL in line with the general assumption that the association between aPL and thrombosis is doubtful in most of the COVID-19 series already published. ${ }^{15}$

Nevertheless, SARS-CoV-2 itself can be responsible for aPL production as reported in other viral and non-viral infections. ${ }^{20}$ Moreover, the occurrence of concomitant infections in moderate/severe COVID-19 may contribute to aPL production as well. In line with the above-mentioned facts, the paper by Trahtemberg et $a l^{21}$ correctly did not check for LA and raised the issue of the right pathological control group including in the study a series of intensive care unit (ICU) patients without SARS-CoV-2 infection but potentially susceptible to the usual comorbidities occurring in ICU patients. The study did not find any significant difference in the presence of a large panel of aPL between ICU patients with and without COVID-19. Such an approach further supports the conclusion that aPL does not seem to be the main player in the COVID-19 thrombophilic microangiopathy. The authors reported an association between aPL serology and more severe disease that, however, was independent of the COVID-19 status.

Moreover, additional findings are supporting the idea that aPL in COVID-19 may represent bystander rather than pathogenic autoantibodies. In fact, there is evidence that this aPL is transient, usually at medium/low titre and frequently of the IgM isotype only. ${ }^{15}$ Moreover, the $\beta 2 \mathrm{GPI}$ dependent aPL was not directed against the domain (D)1 immune-dominant epitope of the molecule but frequently against D4,5. ${ }^{15} 22$ This profile is diametrically

\begin{tabular}{|c|c|c|c|}
\hline Pathogenic paths & APS & CAPS & COVID-19 \\
\hline Thrombotic microangiopathy & $+1-$ & ++ & ++ \\
\hline EC perturbation & + & ++ & ++ \\
\hline Complement activation & + & + & ++ \\
\hline NETosis & $+1-$ & $?$ & ++ \\
\hline Proinflammatory cytokines & $+1-$ & ++ & ++ \\
\hline Impaired fibrinolysis ${ }^{2930}$ & + & $?$ & ++ \\
\hline $\mathrm{aPL}$ & ++ & ++ & $+1-$ \\
\hline
\end{tabular}

aPL, antiphospholipid antibody; APS, antiphospholipid antibody syndrome; CAPS, catastrophic APS; EC, endothelial cell. 
opposite to the persistent high-titre IgG against $\beta 2$ GPI D1 historically reported in autoimmune APS. High-titre anti- $\beta 2$ GPI D1 IgG has been closely associated with the vascular manifestations of the syndrome, was found in human tissue samples affected by APS thrombosis and displayed a thrombogenic effect in animal models at variance with aPL directed against other domains of the molecule. ${ }^{142324}$ Altogether, these findings are in line with the lack of a sound association between aPL and thrombosis reported in the majority of the studies, ${ }^{15}$ and in the paper by Trahtemberg et al. In the same paper, the use of a solid phase assay that was suggested as a surrogate tool for LA further ruled out the presence of aPL theoretically responsible for LA and/or prolonged aPTT. $^{21}$

It is important to keep in mind that patients with COVID-19 suffer from an acute form of systemic inflammation with complement activation, both responsible for endothelial perturbation. ${ }^{8} 911$ In a similar situation, there is evidence that $\beta 2 \mathrm{GPI}$ can accumulate on the activated endothelium at high density, being much more available to the anti- $\beta 2$ GPI antibodies and ultimately favouring their pathogenic effect. ${ }^{25}$ A comparable condition in which low titres of aPL can cause substantial damage was reported in obstetric APS, where high quantities of $\beta 2$ GPI are physiologically expressed in the placenta. ${ }^{26}$ Therefore, while transitory low-titre aPL is likely to be clinically irrelevant in patients with COVID-19 as in other infections, their detection in a disease characterised by a strong inflammatory phenotype raises the issue of whether or not these antibodies may increase the ultimate thrombophilic risk and justify a prophylactic treatment. Accordingly, we could speculate that aPL may affect the clinical severity of the inflammatory disease in ICU patients regardless of the COVID-19 status as shown by Trahtemberg et al. ${ }^{21}$

While the use of prophylactic or therapeutic heparin therapy is widely accepted during the acute phase of the disease, this is still debated during the recovery period or even in the post-COVID-19 follow-up. ${ }^{2}$ Until aPL positive, the patients can theoretically be at higher risk for thrombosis recurrences, and a prophylactic treatment be considered. Unfortunately, we do not have either large follow-up studies evaluating aPL-positive patients with COVID-19 or the best prophylactic regime for such kinds of patients.

If the hypothesis that SARS-CoV-2 is linked with an immune response against PL-binding proteins is true, then the other side of the coin should be represented by the risk of clinical manifestations or the increase in aPL titres in patients suffering from full-blown APS and concomitant SARS-CoV-2 infection. Besides few anecdotical case reports, there is no evidence that this is the case. ${ }^{27} 28$

The use of aPL test in patients with COVID-19 should be taken into consideration in the real life but critically assessed to avoid overinterpretation. For example, as previously discussed, the aPL characterisation in terms of persistence over time, isotype, titre and antigen specificity may help in discriminating between bystander antibodies and pathogenic ones. It is more difficult to draw definite conclusions from a clinical point of view: whether or not the aPL positivity can have a clinical significance to justify a specific treatment in the context of a disease characterised by the production of inflammatory mediators (eg, cytokines, complement activation products) potentially able to downregulate the threshold for endothelial activation.

\section{Handling editor Josef S Smolen}

Contributors PLM and MOB equally contributed in writing the editorial.

Funding The paper was supported in part by Ricerca Corrente 2020 to PLM of the Ministero della Salute, Italy.

\section{Competing interests None declared.}

Patient and public involvement Patients and/ or the public were not involved in the design, or conduct, or reporting, or dissemination plans of this research.

\section{Patient consent for publication Not required.}

Provenance and peer review Commissioned; externally peer reviewed.

(c) Author(s) (or their employer(s)) 2021. No commercial re-use. See rights and permissions. Published by BMJ.

\section{Check for updates}

To cite Meroni PL, Borghi MO. Ann Rheum Dis 2021;80:1105-1107.

Received 21 June 2021

Accepted 15 July 2021

Published Online First 31 July 2021

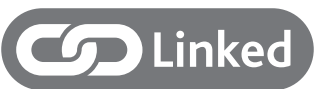

- http://dx.doi.org/10.1136/annrheumdis-2021220206

Ann Rheum Dis 2021:80:1105-1107.

doi:10.1136/annrheumdis-2021-220520

\section{ORCID iDs}

Pier Luigi Meroni http://orcid.org/0000-0002-3394-

1451

Maria Orietta Borghi http://orcid.org/0000-0001-89679678

\section{REFERENCES}

1 Gu SX, Tyagi T, Jain K, et al. Thrombocytopathy and endotheliopathy: crucial contributors to
COVID-19 thromboinflammation. Nat Rev Cardiol 2021:18:194-209.

2 Hadid T, Kafri Z, Al-Katib A. Coagulation and anticoagulation in COVID-19. Blood Rev 2021;47:100761

3 Bowles L, Platton S, Yartey N, et al. Lupus anticoagulant and abnormal coagulation tests in patients with Covid-19. N Eng/ J Med 2020;383:288-90.

4 Zhang Y, Xiao M, Zhang S, et al. Coagulopathy and antiphospholipid antibodies in patients with Covid-19. N Engl J Med 2020;382:e38.

5 El Hasbani G, Taher AT, Jawad A, et al. COVID-19, antiphospholipid antibodies, and catastrophic antiphospholipid syndrome: a possible association? Clin Med Insights Arthritis Musculoskelet Disord 2020:13:117954412097866

6 Previtali G, Seghezzi M, Moioli V, et al. The pathogenesis of thromboembolic disease in covid-19 patients: could be a catastrophic antiphospholipid syndrome? Thromb Res 2020;194:192-4.

7 Colling ME, Kanthi Y. COVID-19-associated coagulopathy: an exploration of mechanisms. Vasc Med 2020:5:471-8.

8 Chauhan AJ, Wiffen LJ, Brown TP. COVID-19: a collision of complement, coagulation and inflammatory pathways. J Thromb Haemost 2020;18:2110-7.

9 Goshua G, Pine AB, Meizlish ML, et al. Endotheliopathy in COVID-19-associated coagulopathy: evidence from a single-centre, cross-sectional study. Lancet Haematol 2020;7:e575-82.

10 Ackermann M, Verleden SE, Kuehnel M, et al. Pulmonary vascular Endothelialitis, thrombosis, and angiogenesis in Covid-19. N Eng/ J Med 2020;383:120-8.

11 Cugno M, Meroni PL, Gualtierotti R, et al. Complement activation and endothelial perturbation parallel COVID-19 severity and activity. J Autoimmun 2021:116:102560.

12 Varga Z, Flammer AJ, Steiger P, et al. Endothelial cell infection and endotheliitis in COVID-19. The Lancet 2020;395:1417-8.

13 Bernard I, Limonta D, Mahal LK, et al. Endothelium infection and dysregulation by SARS-CoV-2: evidence and caveats in COVID-19. Viruses 2020;13:29.

14 Meroni PL, Borghi MO, Raschi E, et al. Pathogenesis of antiphospholipid syndrome: understanding the antibodies. Nat Rev Rheumatol 2011;7:330-9.

15 Taha M, Samavati L. Antiphospholipid antibodies in COVID-19: a meta-analysis and systematic review. RMD Open 2021;7:e001580.

16 Martinuzzo ME, Barrera LH, D 'adamo MA, et al. Frequent false-positive results of lupus anticoagulant tests in plasmas of patients receiving the new oral anticoagulants and enoxaparin. Int I Lab Hematol 2014;36:144-50.

17 Schouwers SME, Delanghe JR, Devreese KMJ. Lupus anticoagulant (lac) testing in patients with inflammatory status: does C-reactive protein interfere with lac test results? Thromb Res 2010;125:102-4.

18 Bertolaccini ML, Amengual O, Andreoli L, et al. 14Th international Congress on antiphospholipid antibodies Task force. Report on antiphospholipid syndrome laboratory diagnostics and trends. Autoimmun Rev 2014;13:917-30.

19 Pengo V, Bison E, Denas G, et al. Laboratory diagnostics of antiphospholipid syndrome. Semin Thromb Hemost 2018:44:439-44

20 Abdel-Wahab N, Talathi S, Lopez-Olivo MA, et al. Risk of developing antiphospholipid antibodies following viral infection: a systematic review and meta-analysis. Lupus 2018:27:572-83.

21 Trahtemberg U, Rottapel R, Dos Santos CC, et al. Anticardiolipin and other antiphospholipid antibodies in critically ill COVID-19 positive and negative patients. Ann Rheum Dis 2021;80:1236-40. 
22 Borghi MO, Beltagy A, Garrafa E, et al. AntiPhospholipid antibodies in COVID-19 are different from those detectable in the anti-phospholipid syndrome. Front Immunol 2020;11:584241.

23 Meroni PL, Macor P, Durigutto P, et al. Complement activation in antiphospholipid syndrome and its inhibition to prevent rethrombosis after arterial surgery. Blood 2016:127:365-7.

24 Durigutto P, Grossi C, Borghi MO, et al. New insight into antiphospholipid syndrome: antibodies to

B2glycoprotein I-domain 5 fail to induce thrombi in rats. Haematologica 2019;104:819-26.
25 Agostinis C, Biffi S, Garrovo C, et al. In vivo distribution of $\beta 2$ glycoprotein I under various pathophysiologic conditions. Blood 2011;118:4231-8.

26 Pregnolato F, Gerosa M, Raimondo MG, et al. Eureka algorithm predicts obstetric risk and response to treatment in women with different subsets of anti-phospholipid antibodies. Rheumatology 2021:60:1114-24.

27 Maria ATJ, Diaz-Cau I, Benejean J-M, et al. Flare of antiphospholipid syndrome in the course of COVID-19. TH Open 2020;4:e207-10.
28 Aguirre-Alastuey ME, Suárez-Díaz S, RodríguezJerez $\mathrm{F}$, et al. Venous thrombosis in a systemic lupus erythematosus patient with antiphospholipid antibodies coinciding with mild Covid-19. Lupus 2021;30:172-4

29 Krone KA, Allen KL, McCrae KR. Impaired fibrinolysis in the antiphospholipid syndrome. Curr Rheumatol Rep 2010;12:53-7.

30 Meizoso JP, Moore HB, Moore EE. Fibrinolysis shutdown in COVID-19: clinical manifestations, molecular mechanisms, and therapeutic implications. $J$ Am Coll Surg 2021:232:995-1003. 